\title{
Single-stage immediate breast reconstruction using a skin-sparing incision and definitive saline implants compared with a two-stage reconstruction using tissue expansion plus implants
}

\author{
Mathew A Plant MD ${ }^{1}$, Christopher G Scilley MD FRCSC ${ }^{2}$, Mark Speechley PhD ${ }^{3}$
}

\begin{abstract}
MA Plant, CG Scilley, M Speechley. Single-stage immediate breast reconstruction using a skin-sparing incision and definitive saline implants compared with a two-stage reconstruction using tissue expansion plus implants. Can J Plast Surg 2009;17(4):117-123.
\end{abstract}

BACKGROUND: Losing a breast to cancer has significant psychological ramifications, and it has been shown that minimizing this loss can have a profound impact. As a result, breast-conserving therapy or mastectomy followed by breast reconstruction have become the preferred surgical treatments for breast cancer. Limited available breast skin following mastectomy has traditionally necessitated the use of autologous tissue or tissue expansion; however, when reconstructing larger breasts, autologous tissue grafts rarely provide enough tissue and tissue expanders can often take several months to achieve the necessary tissue volume. The skin-sparing mastectomy offers a solution to this lack of skin, and as a result many new options for immediate breast reconstruction have presented. The present pilot study looks at a new method of immediate breast reconstruction involving a Wise pattern skin-sparing mastectomy with placement of a definitive, submuscular saline implant as a way to maintain a large breast size without requiring the patient to undergo a long and painful tissue expansion process.

METHODS: A retrospective, case-control study was performed on 12 women who had undergone bilateral mastectomies with immediate reconstruction either with a tissue expander and later placement of definitive saline implant (control group) $(n=5)$ or who had undergone a singlestage reconstruction involving the placement of a definitive submuscular saline implant (experimental group) $(n=7)$. Patients were compared with respect to change in breast size, number of reoperations and operations in total, as well as satisfaction with their reconstruction.

RESULTS: Patient satisfaction in both groups was relatively high and there was no statistically significant difference found between the two groups. The experimental group decreased in bra size by 1.4 cup sizes on however, one-third of patient data had to be discarded for various reasons, making the change in size measurement inconclusive. Finally, the average number of reoperations was higher in the experimental group than the control (1.57 versus 1.00); however, the total number of operations required was less (2.57 versus 2.80 ).

CONCLUSIONS: Immediate breast reconstruction using a definitive submuscular saline implant is a viable option for reconstruction in women with larger breasts that deserves further study on a larger scale. Although limited by sample size, the present pilot study showed, with a large effect size, that this new procedure reduces the total number of operations required for reconstruction when compared with a tissue expander followed by an implant while maintaining an equally high level of patient satisfaction.

Key Words: Breast reconstruction; Implant; Skin-sparing mastectomy average whereas the control group experienced no change on average;

\begin{abstract}
Reconstruction mammaire immédiate en une seule étape à l'aide d'une incision d'épargne cutanée et implant de solution physiologique définitif, comparée à une reconstruction en deux étapes avec expansion tissulaire plus implant
\end{abstract}

CONTEXTE : La perte d'un sein à cause du cancer a des ramifications psychologiques importantes et il a été démontré que le fait d'atténuer cette perte peut avoir un impact marqué. Par conséquent, le traitement de conservation mammaire ou de mastectomie suivie de reconstruction mammaire est devenu le traitement privilégié dans le cancer du sein. La faible quantité de peau mammaire disponible après la mastectomie a traditionnellement nécessité l'emploi de greffes de tissu autologue ou d'expanseurs tissulaires. Toutefois, au moment de reconstruire des seins plus volumineux, les greffes de type autologue procurent rarement suffisamment de tissu et les expanseurs tissulaires demandent souvent plusieurs mois pour produire le volume nécessaire. La mastectomie avec épargne cutanée offre une solution à ce problème et de nombreuses nouvelles options pour la reconstruction mammaire immédiate ont ainsi été présentées. L'étude pilote actuelle se penche sur une nouvelle méthode de reconstruction mammaire immédiate au moyen d'une mastectomie d'épargne cutanée selon la technique de Wise avec installation d'un implant de solution physiologique sous-musculaire définitif comme façon d'obtenir un sein de taille volumineuse sans que la patiente doive subir un processus d'expansion tissulaire long et douloureux.

MÉTHODES : Une étude rétrospective avec cas-témoins a été réalisée auprès de 12 femmes qui ont subi des mastectomies bilatérales avec reconstruction immédiate, soit au moyen d'un expanseur tissulaire avec pose ultérieure d'un implant de solution physiologique définitif (groupe témoin) $(\mathrm{n}=5)$, soit au moyen d'une reconstruction en une étape avec pose d'un implant de solution physiologique sous musculaire définitif (groupe expérimental) $(\mathrm{n}=7)$. Les patientes ont été comparées en ce qui a trait au changement de la taille du sein, au nombre de réinterventions et d'interventions totales et à leur satisfaction à l'endroit de la reconstruction.

RÉSULTATS : La satisfaction des patientes des deux groupes a été relativement élevée et on n'a noté aucune différence statistiquement significative entre les deux groupes. Le groupe expérimental est passé à un bonnet de soutien-gorge de 1,4 taille plus petite en moyenne, tandis que le groupe témoin n'a présenté aucun changement en moyenne. Toutefois, le tiers des données des patientes ont dû être éliminées pour diverses raisons, ce qui rend les mesures de changement de taille non concluantes. En terminant, le nombre moyen de réinterventions a été plus élevé dans le groupe expérimental que dans le groupe témoin $(1,57$ versus 1,00$)$. Toutefois, le nombre total d'opérations requises a été inférieur (2,57 versus 2,80).

CONCLUSIONS : La reconstruction mammaire immédiate à l'aide d'un implant de solution physiologique sous-musculaire définitif est une option envisageable pour la reconstruction chez les femmes ayant des seins volumineux. Cette approche mérite qu'on l'étudie sur une plus grande échelle. Bien que limitée par la taille de l'échantillon, la présente étude pilote a révélé avec une importante valeur de l'effet que cette nouvelle intervention réduit le nombre total d'interventions requises pour la reconstruction lorsqu'on la compare à un expanseur tissulaire suivi d'un implant tout en maintenant un degré aussi élevé de satisfaction chez les patientes.

${ }^{1}$ Division of Plastic Surgery, Department of Surgery, The University of Toronto, Toronto; ${ }^{2}$ Division of Plastic Surgery, Department of Surgery, The Schulich School of Medicine and Dentistry; ${ }^{3}$ Department of Epidemiology $\mathcal{E}$ Biostatistics, The University of Western Ontario, London, Ontario Correspondence: Dr Christopher G Scilley, London Health Sciences Centre - Victoria Campus, Room E2-214, 800 Commisioners Road East, PO Box 5010, London, Ontario N6A 5W9. Telephone 519-667-6755, fax 519-667-6627, e-mail cscilley@uwo.ca 
L osing a breast to cancer has significant psychological and sexual ramifications to the patient (1), and one goal of patient-centred care for the breast cancer patient is to minimize these effects. It has been shown that methods that minimize this loss can have a profound impact on the patient's psychological wellbeing $(1,2)$. As a result of this, the radical mastectomy has become less common in favour of wide local excision/breast-conserving therapy (BCT) or mastectomy followed by breast reconstruction. Studies have shown that of the three options available - simple mastectomy, BCT and mastectomy followed by reconstruction - BCT offers the best psychological outcome because it leaves the woman's body 'intact' $(1,2)$; however, it is not always an oncologically safe option, and in these instances the entire breast must be removed. When this is the case, it has been shown that reconstructing the breast leads to a better psychological outcome and a better quality of life in women who have undergone a mastectomy $(1,3)$. Furthermore, it has been demonstrated that women who have immediate breast reconstruction fare better, especially in sexual functioning, than those who opted for a delayed reconstruction. In fact, many of those who chose a delayed reconstruction said in retrospect that given their current knowledge they would have instead chosen an immediate reconstruction (3).

Since the advent of the silicone breast implant in 1963 there has been a focus on breast reconstruction as an important part of the treatment of the breast cancer patient. Various methods have been attempted to achieve an end result as close to the patient's premastectomy appearance as possible, minimizing the psychological impact relating to the often deforming treatments associated with the disease.

In addition to achieving the best cosmetic results, the surgeon must take into account the oncological safety of the mastectomy and reconstruction procedure(s) as well as account for any potential interactions with postmastectomy adjuvant treatments such as chemotherapy and radiotherapy. As a result, the focus has traditionally been on delayed reconstructions following radical mastectomy, often requiring many invasive procedures and repeat operations to achieve a final, cosmetically acceptable result (4).

The skin-sparing mastectomy (SSM) was first described by Toth et al (5) in 1991 as an attempt to maximize skin preservation to facilitate a more cosmetically pleasing postreconstructive result. This procedure involves removing the nipple-areola complex, as well any skin within $1 \mathrm{~cm}$ of the tumour and all breast tissue, allowing for preservation of the natural inframammary fold, which results in better symmetry with the contralateral breast and a more natural appearance of the reconstructed breast.

The SSM has been deemed oncologically safe (6-8) for both low- and high-risk patients and has been studied in those with up to stage IIIb disease and greater than four positive lymph nodes (9), which represents the vast majority of women requiring mastectomy (10). Several patterns for skin-sparing incisions have been described including the periareolar approach, the modified ellipse, the omega pattern (11), the reduction ('Wise') pattern, as well as several combinations of these incisions (7). To repair the defect left by the mastectomy, various methods have been described, often involving autologous tissue grafts including the transverse-rectus abdominis myocutaneous flap
(12), the latissimus dorsi flap with or without implant $(4,9)$, the deep inferior epigastric perforator flap (12) or the gluteal artery perforator flap (12). Alternatively, the reconstruction may include immediate definitive silicone implants (13), tissue expanders with later definitive implants (12), adjustable definitive implants (14), or combinations of autologous tissue grafts and implants. As a result of these advances, a recent trend has been to use one of the SSM techniques followed by immediate breast reconstruction as it has been shown to improve cosmetic outcomes without negatively impacting on postmastectomy adjuvant therapy (4).

The first method described for immediate reconstruction was to use a definitive implant; however, due to a lack of adequate breast tissue following radical mastectomy the final appearance was a round, fixed breast that was not cosmetically acceptable to the majority of women (13). Because of this, as well as concerns over oncological safety, the immediate reconstruction became a rare occurrence. Instead, to add tissue to the area, surgeons began using the radical elliptical mastectomy followed by reconstruction with autologous tissue grafts or staged skin expansion with later definitive implants (13). With the increased use and proven safety of the SSM, the trend has shifted back toward minimizing reconstruction reoperations, instead favouring a one- or two-stage reconstruction beginning at the initial mastectomy.

While the autologous tissue grafts provide excellent results for women with smaller breasts, they rarely provide enough tissue to adequately reconstruct a larger breast. A similar problem exists with staged reconstructions involving expanders as it can take several years to achieve the necessary tissue volume to accept a definitive implant large enough to recreate the preoperative breast size. Hammond et al (15) described a procedure using tissue expanders followed by a definitive implant that can be used to maintain breast size in largebreasted women where the undesirable round, fixed shape of the implanted breast is eliminated. This procedure uses the Wise pattern SSM to maintain the natural inframammary fold and a large enough skin envelope at the lower pole of the breast to facilitate the release of the lower border of the pectoral muscle pocket, allowing the tissue expander, and later implant to sit in a more natural position than that resulting from a traditional subpectoral pocket with an intact lower border (15). The senior author of the present paper (CGS) has adapted this procedure to allow for the immediate placement of a definitive implant, eliminating the tissue expansion required in the procedure described by Hammond et al, and decreasing the number of re-operations likely to be needed. The senior author has successfully performed seven of these operations since 2001 and the anecdotal results look very promising. The objectives of the present pilot study are to assess the outcomes of this procedure in terms of patient satisfaction, maintenance of breast size, reoperation rate and total number of operations. The results will add to our knowledge of the viability of this one-stage procedure for reconstruction and assist in sample size calculations for a prospective experimental study. Our hypothesis is that the one-stage implant reconstruction will decrease the total number of operations patients require to achieve an adequate result while maintaining breast size and patient satisfaction comparable with the two-stage tissue expander reconstruction. 


\section{PATIENTS AND METHODS}

\section{Patients}

The retrospective case control study design was approved by the University of Western Ontario (London, Ontario) Research Ethics Board, and all subjects gave informed consent. Twelve women were included, all of whom had undergone an immediate reconstruction of both breasts following a bilateral mastectomy due to either bilateral breast carcinoma or a unilateral carcinoma with a contralateral prophylactic mastectomy. Patients were limited to those whose operations had occurred between January 2001 and March 2007. With the exception of the skin incision, all patients underwent a standard modified radical mastectomy with or without a sentinel node biopsy according to the oncological safety standards of the general surgeon performing the mastectomy. The size of tissue expander and/or final implant was determined preoperatively in discussion with the patients according to their current preoperative and desired postoperative breast sizes. The mean $( \pm$ SD) age at the time of operation was $44.06 \pm 10.40$ years (range 29 to 55 years).

A chart review abstracted information on age, height, weight, smoking status at the time of operation, pre- or postoperative radiation, final volume of implants placed, number of reoperations required to achieve the desired aesthetic effect or correct complications, and total number of operations. The values for total number of operations included the initial reconstruction, the placement of the final implant (for the control group patients) and all reoperations required to achieve a satisfactory result. For the purposes of the present study, nipple-areola complex reconstruction was considered to be an optional ancillary surgery and thus was not included in the calculation of reoperation rates and total number of operations.

Patients were also mailed a questionnaire to assess their preoperative and postoperative bra size, smoking status at the time of surgery, as well as the presence of comorbidities that may affect wound healing (eg, diabetes mellitus, cardiovascular disease, peripheral vascular disease, immunodeficiency and coagulopathies) and or their general satisfaction (eg, depression, dysthymia, schizophrenia and bipolar disorder). Bra size was coded into numerical values (Table 1) to permit the calculation of change in cup size (defined as postoperative cup size - preoperative cup size). Body mass index was then calculated as weight in kilograms divided by height in meters squared.

To assess their subjective satisfaction, patients were asked to indicate their level of agreement with seven statements based on a modification of the scale used in the Michigan Breast Reconstruction Outcome Study (16) and answers were measured on a five-point Likert scale ranging from 'strongly disagree' to 'strongly agree' (Figure 1) (17). Because the sample size was relatively small and patient satisfaction with any type of breast reconstruction is generally high $(16,18)$ it was thought that questions 2, 3 and 4 should be the focus for the present study because they were likely the best indicators that the patient was truly satisfied with the procedure. This was because positive responses to these questions indicated that the patient would make the same decision over if given the opportunity (question 2), they were satisfied overall (question 3 ), and would recommend the procedure to a friend (question 4).
TABLE 1

Bra size and associated numeric values

\begin{tabular}{lc}
\hline Bra size & Numeric value \\
\hline A & 1 \\
B & 2 \\
C & 3 \\
D & 4 \\
DD & 5 \\
E & 6 \\
\hline
\end{tabular}

\section{Reconstruction Satisfaction Statements}

Patients were asked to indicate their level of agreement with the following statements:

1.) Knowing what I know today, I would definitely choose to have breast reconstruction

2.) Knowing what I know today, I would definitely choose to have the type of breast reconstruction I had

3.) Overall I am satisfied with my reconstruction

4.) I would recommend the type of reconstructive procedure I had to a friend

5.) I felt that I received sufficient information about my reconstructive options to make an informed choice

6.) The size and shape of my breasts are the same

7.) My reconstructed breasts feel soft to the touch

Figure 1) Patient satisfaction survey questions

\section{Control group}

Five women were identified as having had an immediate bilateral breast reconstruction using tissue expanders and were included in the control group. All control patients underwent a modified radical mastectomy with or without sentinel node biopsy using the standard elliptical incision. The general surgeons were not asked to change their operation in any way to facilitate the subsequent reconstruction. Before skin closure, the plastic surgery team took over, dissected out a subpectoral pocket and released the inferior border of the pectoralis major muscle in the standard fashion, placed a tissue expander and then proceeded to close the skin primarily. The tissue was expanded over three to six months until a sufficient volume for the desired implant was achieved, and the patient was taken back to the operating room to have the tissue expander removed and replaced with a definitive implant. The mean age of the control group at time of operation was $40.9 \pm 11.9$ years.

\section{Experimental group}

Seven women were identified as having had an immediate bilateral breast reconstruction using a definitive implant without an intervening tissue expansion process and were included in the experimental group. All patients were marked preoperatively by the plastic surgeon for a Wise pattern incision (Figure 2), which included a resection of the nipple-areola complex to be performed by the general surgeon. A standard modified radical mastectomy with or without sentinel node biopsy was then performed through this incision and the skin flaps were left intact (Figure 3). Following the mastectomy, the plastic surgery team took over and first de-epithelialized the inferior flap (Figure 4). Next, they dissected out a subpectoral pocket and released the inferior border of the pectoralis major muscle (Figure 5). A saline implant was then placed in the 


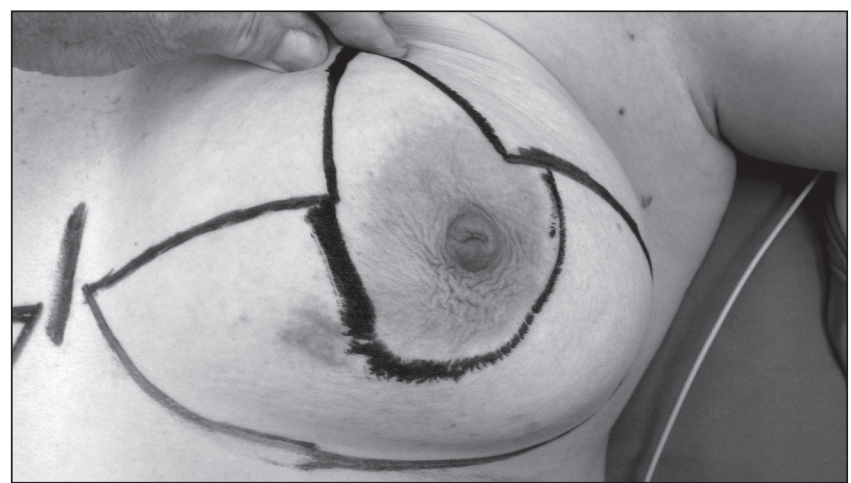

Figure 2) Preoperative breast markings in the 'Wise pattern' delineating the superior and inferior flaps as well as the removal of the nipple-areola complex

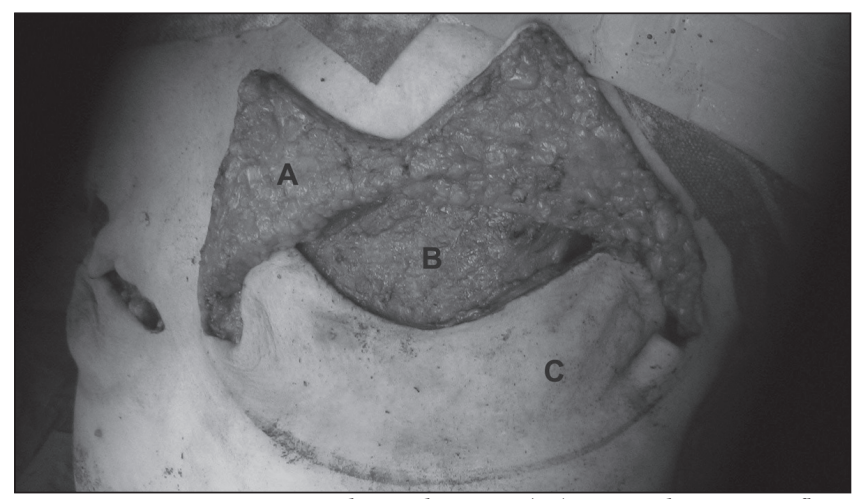

Figure 3) Intraoperative photo showing (A) everted superior flap, (B) pectoralis major muscle and (C) inferior skin flap

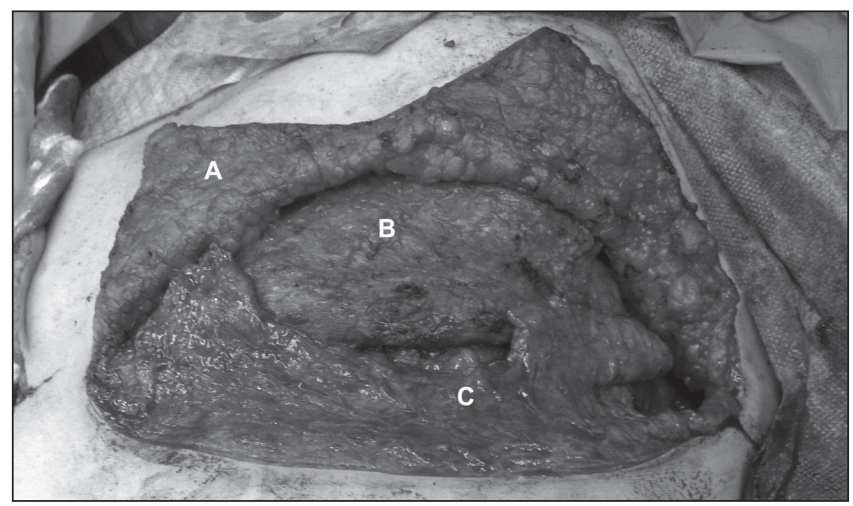

Figure 4) Intraoperative photo showing (A) everted superior flap, (B) pectoralis major muscle and (C) deepithelialized inferior skin flap

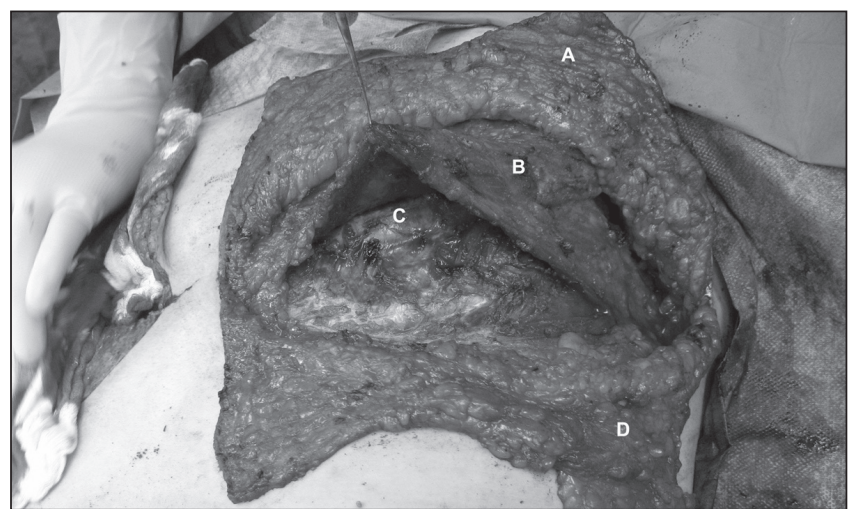

Figure 5) Intraoperative photo showing (A) everted superior skin flap, (B) pectoralis major muscle, (C) subpectoral implant pocket and $(D)$ everted inferior skin flap

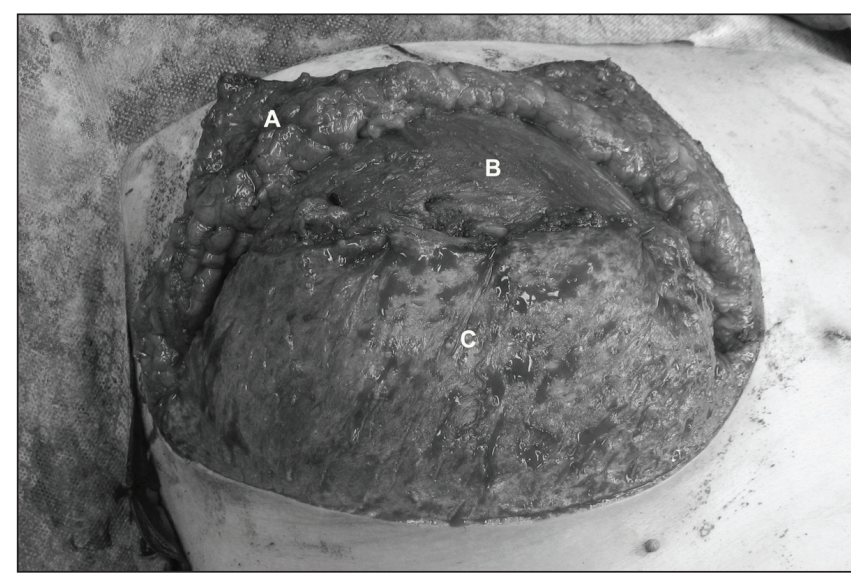

Figure 6) Intraoperative photo showing (A) everted superior skin flap, (B) pectoralis major muscle sutured to (C) deepithelialized inferior skin flap

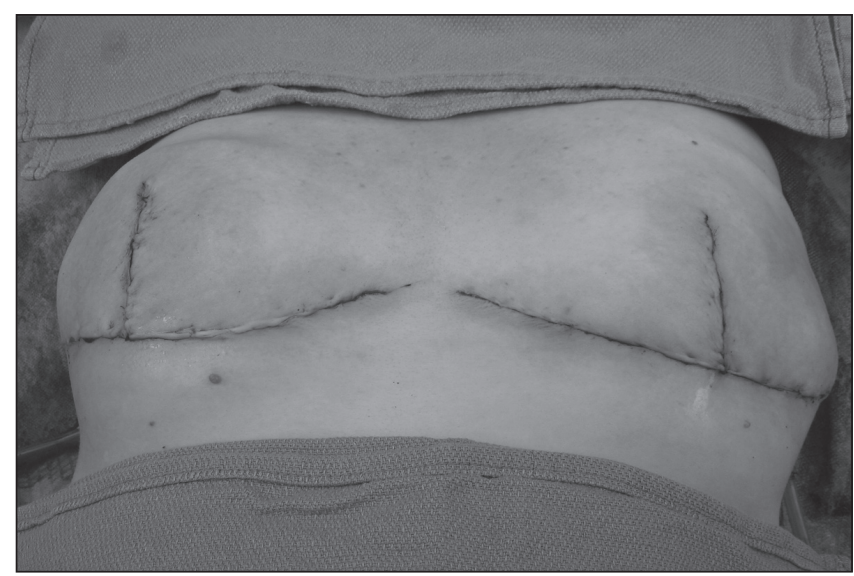

Figure 7) Intraoperative photo showing final everted-T closure

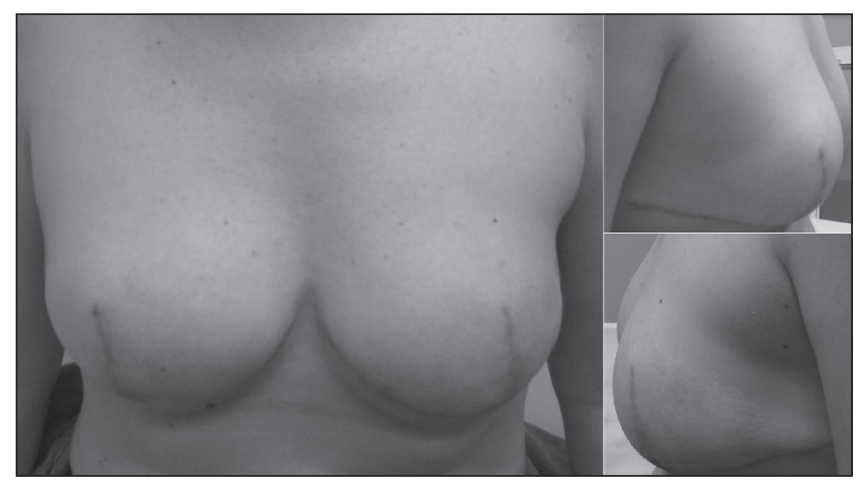

Figure 8) Three-month postoperative photo showing reconstructed breasts from anterior, left and right profiles

submuscular pocket and the deepithelialized inferior flap was then sutured to the inferior border of the pectoralis major with the inferior pole of the implant sitting below the edge of the released pectoral in the natural inframammary fold (Figure 6). The superomedial and superolateral skin was then closed primarily in a vest-over-pants fashion (Figures 7 and 8). The average age of the experimental group at time of operation was $46.3 \pm 9.5$ years.

\section{Statistical analysis}

To estimate the effect size observed in the present small study, and to assist in sample size calculations for a definitive trial, 
TABLE 2

Final volume of saline implants, preoperative and postoperative bra sizes and change in cup size

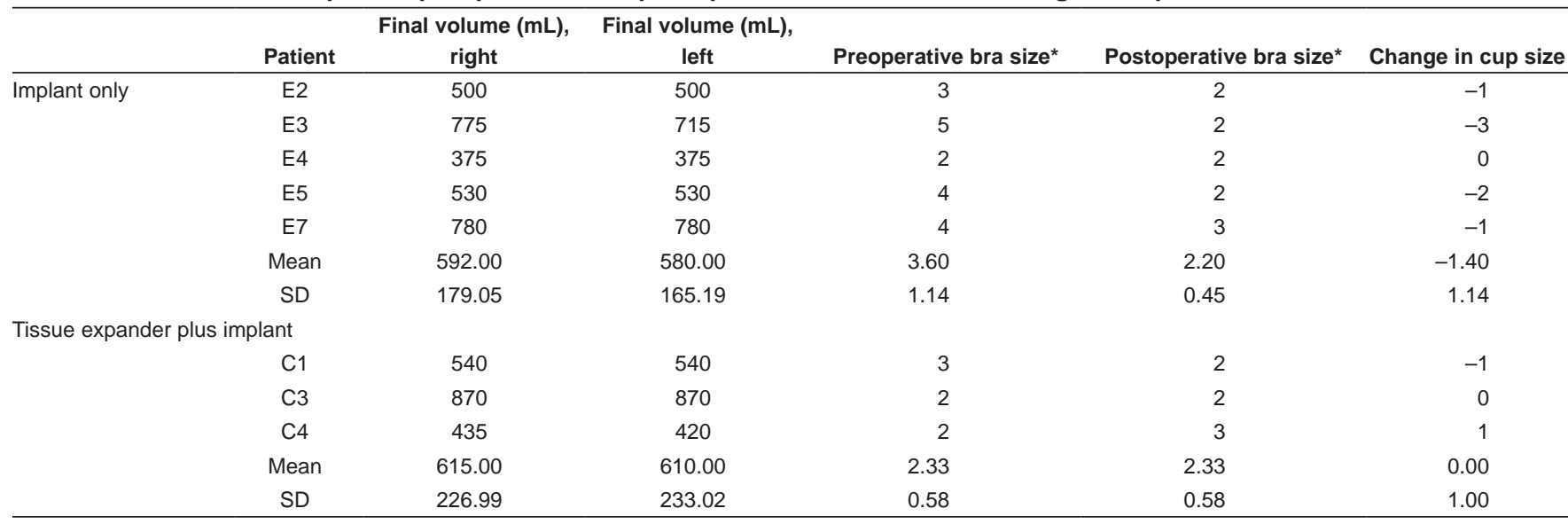

*See Table 1. C Control group; E Experimental group

Cohen's effect size h (for binary variables) was calculated for the observed difference in proportion of patients requiring one or more reoperations, and Cohen's effect size d (for continuous variables) was calculated for the observed differences in the means of total operations, change in cup size and satisfaction scale scores between the groups. For both $\mathrm{d}$ and $\mathrm{h}$ statistics, Cohen's qualitative descriptors of effect size are 'small' (0.2), 'moderate' (0.5) and 'large' (0.8) (19).

\section{RESULTS}

With respect to the surveys, all but one (from a control patient) were returned and, as seen with the vast majority of breast reconstruction studies, the patients were generally quite satisfied $(16,18)$. The average satisfaction scores in both the experimental and control groups were quite similar. Cohen's effect size d was then calculated and determined to be 0.19, 0.0 and 0.27 , respectively, for these questions.

The groups were then compared with respect to average change in cup size (Table 2); however, in interpreting these results, the data from three patients had to be disregarded. Patients E1 and E6 had failed their implant reconstructions and had gone on to a secondary reconstruction with bilateral latissimus dorsi flaps with saline implants, and patient C2 had failed her implant reconstruction and undergone a secondary bilateral transverse-rectus abdominis myocutaneous flap reconstruction; thus, their postoperative bra sizes represented the final appearance of these reconstructions and not the ones being investigated in the present paper. Finally, patient C5 did not return her survey, and therefore her preoperative and postoperative bra sizes were not available.

Once the data were compiled, it was seen that the experimental group patients began with an average cup size of 3.60 (large $\mathrm{C}$ cup) and the control group had an average of 2.33 (small B cup), indicating that the experimental group patients were on average more than one full cup size larger than those in the control group before surgery. After surgery, the experimental group had decreased their average cup size to 2.20 whereas the average control group cup size was maintained at 2.33. This indicated an average reduction of 1.4 cup sizes in the experimental group compared with an average loss of 0 cup
TABLE 3

Patient data for number of operations and reoperations

\begin{tabular}{lccc}
\hline Patient & Patient & $\begin{array}{c}\text { Number of } \\
\text { reoperations }\end{array}$ & $\begin{array}{c}\text { Total number of } \\
\text { operations }\end{array}$ \\
\hline Implant only & E1 & 4 & 5 \\
E2 & 1 & 2 \\
E3 & 0 & 1 \\
E4 & 0 & 1 \\
E5 & 0 & 1 \\
E6 & 4 & 5 \\
E7 & 2 & 3 \\
Mean & 1.57 & 2.57 \\
SD & 1.81 & 1.81 \\
Tissue expander plus implant & & 2 \\
C1 & 0 & 5 \\
C2 & 4 & 2 \\
C3 & 0 & 3 \\
C4 & 1 & 2 \\
C5 & 0 & 1.30 \\
Mean & 1.00 & \\
SD & 1.73 & 2.80 \\
\hline
\end{tabular}

C Control group; E Experimental group

sizes in the control group. The Cohen's effect size d was equal to 1.3 , a 'large' effect size, which is likely clinically significant.

Finally, the average number of operations and reoperations were calculated (Table 3), demonstrating that although the experimental group had a higher average reoperation rate $(1.57$ versus 1.00$)$, it still maintained a lower total number of operations (2.57 versus 2.80). A Cohen's effect size h was calculated for the proportion of patients in each group that had required one or more reoperations (four of seven in the experimental group, and two of five in the control group) and determined to be 0.34 . A Cohen's effect size $d$ was calculated for the mean numbers of operations in total between the groups and found to be 0.14 .

The data were then re-analyzed with the information from the three smokers in the study removed and a dramatic difference was seen (Table 4). The proportion of patients requiring one or more reoperations decreased from four of seven to two of 


\section{TABLE 4}

Patient data for number of operations and reoperations. Data from smokers were removed

\begin{tabular}{cccc}
\hline Patient & $\begin{array}{c}\text { Number of } \\
\text { reoperations }\end{array}$ & $\begin{array}{c}\text { Total number of } \\
\text { operations }\end{array}$ \\
\hline Implant only & E2 & 1 & 2 \\
E3 & 0 & 1 \\
E4 & 0 & 1 \\
E5 & 0 & 1 \\
E7 & 2 & 3 \\
Mean & 0.60 & 1.60 \\
SD & 0.89 & 0.89 \\
Tissue expander plus implant & & 2 \\
C1 & 0 & 2 \\
C3 & 0 & 3 \\
C4 & 1 & 2 \\
C5 & 0 & 2.25 \\
Mean & 0.25 & 0.50 \\
SD & 0.50 & \\
\hline
\end{tabular}

C Control group; E Experimental group

five ( $57 \%$ to $40 \%$ ) in the experimental group and from two of five to one of four (40\% to $25 \%$ ) in the control group. The average reoperation rates also declined drastically from 1.57 to 0.60 in the experimental group and 1.00 to 0.25 in the control. These correlate to a Cohen's effect size $\mathrm{h}$ of 0.32 for the proportion of patients requiring one or more reoperations, and a Cohen's effect size d of 0.93 for the differences in the mean total number of operations between the groups.

\section{DISCUSSION}

Although the sample size for the present pilot study was too small for formal hypothesis testing, some of the results suggest that the new procedure may yield clinically significant effects relative to the conventional approach.

With respect to the three survey statements focused on, the effect sizes $(0.19,0.0$ and 0.27 , respectively) suggest that the differences between the groups were small. Sample size calculations indicate that between 200 and 400 patients in each group would be required to have $80 \%$ power to demonstrate a statistically significant difference between groups with a $\mathrm{P}<0.05$.

With regards to the change in cup size, the Cohen's effect size d equal to 1.3 indicates that there was in fact a large, and potentially real, decrease in the cup size of the experimental group with respect to the control group. However with four of our 12 patients' data being thrown out for various reasons, it is difficult to place much weight on these data with respect to guiding future practice. Furthermore, in looking at the raw data, it can be seen from patient E7 that it is certainly possible to maintain at least a $\mathrm{C}$ cup. As this procedure is performed more often, its true ability or inability to maintain a large cup size will be determined. In fact, a sample size calculation for this variable based on the effect size of 1.3 , indicates that a study would have $80 \%$ power to determine this with a $\mathrm{P}<0.05$ with two groups of 11 women.

Finally, with respect to the reoperation rates and total number of operations, it was noted that, with the exception of three patients who had undergone four reoperations, all members of the study required two or fewer reoperations. In light of this observation, the raw data were re-examined to determine why each of these three patients might have required so many reoperations compared with the rest of the cohort, and whether there was any common variable that may be linking these three cases. It was determined that all three were the patients noted in the Results section who had failed the initial reconstruction and had gone on to have a second reconstruction using autologous tissue. It was further determined that all three had failed their initial reconstructions due to wound healing issues, and that all three were smokers as well (in fact, the only three smokers in the study). Comparing the Cohen's effect size $\mathrm{h}$ for patients requiring one or more reoperations in the entire cohort compared with the nonsmokers only ( 0.34 versus 0.32 , respectively) the difference is negligible; however, when the effect size $\mathrm{d}$ for the mean total number of operations ( 0.14 versus 0.93 , respectively) is compared, there is certainly a clinically significant difference seen. This essentially means that without the negative effects of smoking on wound healing, the new procedure on average decreases the total number of operations required by one full operation, which is what was expected in attempting to perform a reconstruction in one stage instead of two. With an effect size of 0.93 , a sample size of 26 per group would be required to determine with $\mathrm{P}<0.05$ that the new procedure does in fact significantly decrease the total number of operations required for an implant reconstruction in a nonsmoking population.

Despite the small sample size of the study, much clinically significant information can be inferred from the large effect sizes seen. First and foremost, it appears as though patient satisfaction is essentially the same whether a patient undergoes a two-stage reconstruction involving tissue expanders with later implantation or a one-stage reconstruction with a definitive implant. Second, although it appears as though the patients who have undergone a one-stage reconstruction have a higher reoperation rate, on a population basis it seems as though the total number of operations required is in fact decreased. Furthermore, as with any surgical procedure, patient factors - most importantly smoking status - appear to have a profound impact on the outcome of this one-stage reconstruction, and when controlled for, the decrease in required operations is even more apparent. Finally, although the statistical data in this study indicated that there was a decrease in final breast size when comparing the one-stage implant reconstruction with the two-stage tissue expander reconstruction, the fact that the experimental patients began with a much larger average cup size, that a full $25 \%$ of the patients had unusable data for this parameter, and that the anecdotal evidence suggests a fairly large breast can be maintained, indicates that this observation should be weighted less than the others when deciding whether to offer this procedure to patients seeking immediate breast reconstruction until it can be studied in further detail.

\section{CONCLUSIONS}

It appears from the present pilot study as though a one-stage, immediate breast reconstruction using a definitive implant is most certainly a viable reconstructive option to be offered to certain patients, and that in a nonsmoking patient population it can certainly decrease the total number of operations required while maintaining a high level of patient satisfaction. In our opinion the present pilot study indicates that this procedure deserves further study in a prospective, randomized control trial with a sample size on the order of 26 nonsmoking women per group. 


\section{REFERENCES}

1. Al-Ghazal SK, Fallowfield L, Blamey RW. Comparison of psychological aspects and patient satisfaction following breast conserving surgery, simple mastectomy and breast reconstruction. Eur J Cancer 2000;36:1938-43.

2. Rowland JH, Desmond KA, Meyerowitz BE, Belin TR, Wyatt GE, Ganz PA. Role of breast reconstructive surgery in physical and emotional outcomes among breast cancer survivors. J Natl Cancer Inst 2000;92:1422-9. (Erratum in 2001;93:68).

3. Al-Ghazal SK, Sully L, Fallowfield L, Blamey RW. The psychological impact of immediate rather than delayed breast reconstruction. Eur J Surg Oncol 2000;26:17-9.

4. Losken A, Carlson GW, Schoemann MB, Jones GE, Culbertson JH, Hester TR. Factors that influence the completion of breast reconstruction. Ann Plast Surg 2004;52:258-62.

5. Toth BA, Forley BG, Calabria R. Retrospective study of the skinsparing mastectomy in breast reconstruction. Plast Reconstr Surg 1999;104:77-84.

6. Carlson GW, Bostwick J 3rd, Styblo TM, et al. Skin-sparing mastectomy: Oncologic and reconstructive considerations. Ann Surg 1997;225:570-8.

7. Chagpar AB. Skin-sparing and nipple-sparing mastectomy: Preoperative, intraoperative, and postoperative considerations. Am Surg 2004;70:425-32.

8. Vaughan A, Dietz JR, Aft R, et al. Patterns of local breast cancer recurrence after skin-sparing mastectomy and immediate breast reconstruction. Am J Surg 2007;194:438-43.

9. Downes KJ, Glatt BS, Kanchwala SK, et al. Skin-sparing mastectomy and immediate reconstruction is an acceptable treatment option for patients with high-risk breast carcinoma. Cancer 2005;103:906-13.
10. Morrow M, Scott SK, Menck HR, Mustoe TA, Winchester DP. Factors influencing the use of breast reconstruction postmastectomy: A National Cancer Database study. J Am Coll Surg 2001;192:1-8.

11. Vlajcic Z, Zic R, Stanec S, Stanec Z. Omega and inverted omega incision: A concept of uniform incision in breast surgery. Ann Plast Surg 2004;53:31-8

12. O'Shaughnessy K, Fine N. Issues related to choice of breast reconstruction in early-stage breast cancer. Curr Treat Options Oncol 2006;7:129-39.

13. Salgarello M. Farallo,E. Immediate breast reconstruction with definitive anatomical implants after skin-sparing mastectomy. Br J Plast Surg 2005;58:216-22.

14. Eskenazi LB. New options for immediate reconstruction: Achieving optimal results with adjustable implants in a single stage. Plast Reconstr Surg 2007;119:28-37.

15. Hammond DC, Capraro PA, Ozolins EB, Arnold JF. Use of a skinsparing reduction pattern to create a combination skin-muscle flap pocket in immediate breast reconstruction. Plast Reconstr Surg 2002;110:206-11.

16. Alderman AK, Wilkins EG, Lowery JC, Kim M, Davis JA. Determinants of patient satisfaction in postmastectomy breast reconstruction. Plast Reconstr Surg 2000;106:769-76.

17. Shaikh-Naidu N, Preminger BA, Rogers K, Messina P, Gayle LB. Determinants of aesthetic satisfaction following TRAM and implant breast reconstruction. Ann Plast Surg 2004;52:465-70.

18. Saulis AS, Thomas AM, Fine NA. A retrospective analysis of patient satisfaction with immediate postmastectomy breast reconstruction: Comparison of three common procedures. Plast Reconstr Surg. 2007;119:1669-76.

19. Cohen J. Statistical Power Analysis for the Behavioral Sciences, 2nd edn. Hillsdale, New Jersey: L Erlbaum Associates, 1988. 